American Journal of Applied Sciences 9 (1): 75-82, 2012

ISSN 1546-9239

(C) 2012 Science Publications

\title{
Vitamin E Mitigates Chronic Chlorpyrifos-Induced Oxidative Changes in Pituitary Glands and Testes in Wistar Rats
}

\author{
${ }^{1}$ M. Shittu, ${ }^{1}$ J.O. Ayo, ${ }^{1}$ S.F. Ambali, ${ }^{1}$ M.U. Kawu and ${ }^{2}$ S.O. Salami \\ ${ }^{1}$ Department of Veterinary Physiology and Pharmacology, \\ ${ }^{2}$ Department of Veterinary Anatomy, \\ Ahmadu Bello University, Zaria, Nigeria
}

\begin{abstract}
Problem statement: The sperm counts of men have declined by about 50\% in the last few decades. The contribution of environmental contaminants to this decline cannot be overemphasized. Pesticide is one of the most pervasive environmental chemical contaminants that have been of increased use due to the compelling need to feed the ever-growing world human and animal population and protect their health. Chlorpyrifos (CPF), a widely used Organophosphate (OP) insecticide has been reported to alter male reproductive hormones and semen characteristics. Apart from acetyl cholinesterase inhibition, the induction of oxidative stress is one of the molecular mechanisms implicated in CPF poisoning. Approach: The present study was aimed at evaluating the effect of vitamin $\mathrm{E}$ in mitigating oxidative damage to the pituitary gland and the testis, induced by chronic CPF administration in Wistar rats. Methodology: Twenty adult male Wistar rats divided into 4 groups of 5 rats in each group were used for this study. Group I received soya oil $\left(2 \mathrm{~mL} \mathrm{~kg}^{-1}\right)$, while Group II was administered vitamin E $\left(75 \mathrm{mg} \mathrm{kg}^{-1}\right)$; Group III was administered CPF only $\left(10.6 \mathrm{mg} \mathrm{kg}^{-1} \sim 1 / 8\right.$ th $\left.\mathrm{LD}_{50}\right)$, while group IV was pretreated with vitamin $\mathrm{E}\left(75 \mathrm{mg} \mathrm{kg}^{-1}\right)$ and exposed to CPF $\left(10.6 \mathrm{mg} \mathrm{kg}^{-1}\right)$ $30 \mathrm{~min}$ later. The regimens were administered orally by gavages once daily for a period of 15 weeks. At the end of the treatment period, the rats were sacrificed and the pituitary glands and testicular tissues were assayed for the concentrations of Malonaldehyde (MDA) and the activities of Superoxide Dismutase (SOD) and Catalane (CAT). Results: The result showed that the increase in concentrations of pituitary and testicular MDA and a decrease in the activities of SOD and CAT recorded in the group exposed to CPF were ameliorated by pretreatment with vitamin E. Conclusion: This indicates that vitamin E mitigates reproductive toxicity induced by chronic CPF exposure due to its protective antioxidant activity on pituitary glands and the testes.
\end{abstract}

Key words: Oxidative stress, pituitary gland, vitamin E, Luteinizing Hormone (LH), Superoxide Dismutase (SOD), Catalane (CAT), Malonaldehyde (MDA), Organophosphates (OP), Acetyl Cholinesterase (AChE)

\section{INTRODUCTION}

The increase in human and animal population, especially in the last few decades, has led to the compelling need to increase food production. The development of high-yielding crop varieties and the formulation of more potent pesticides to aid in the elimination of pests that destroy crops are therefore imperative (Joshi et al., 2005). Organophosphates (OP) insecticides are widely used for the control of insect pests (Vidyasagar et al., 2004) as it account for 50\% of global insecticide use (Casida and Quistad, 2004).
Therefore, the tendency for human and animal exposure in both rural and residential environment is common (Ngoula et al., 2007). The main mechanism of action of OP is inhibition of the activity of Acetyl Cholinesterase (AChE), an enzyme essential for normal neuronal transmission in living organisms (Abou-Donia, 2003).

Chlorpyrifos (CPF) is a broad spectrum OP insecticide that has gained popularity in domestic, industrial and agricultural pest control (Lemus and Abdelghani, 2000). It is of relatively moderate mammalian toxicity (Kenaga et al., 1965). Since its

Corresponding Author: M. Shittu, Department of Veterinary Physiology and Pharmacology, Ahmadu Bello University, Zaria, Nigeria Tel: +2348036944273 
introduction into the American market in 1965, CPF has been used in agricultural crop protection (Lassiter and Brimijoin, 2008) and occasional use for the control of ticks on cattle (Eaton et al., 2008). Despite the restriction placed on some of its domestic applications by the United States Environmental Protection Agency (USEPA, 2000), its presence is being reported within the general population, indicating on-going environmental exposure (Meeker et al., 2006; Whyatt $e t$ al., 2007). Like many OP compounds, the primary but not necessarily the main mechanism of action of $\mathrm{CPF}$ is the inhibition of AChE by the oxon metabolite of CPF, leading to the inhibition of the neurotransmitter ACh at cholinergic target tissues (Eaton et al., 2008). However, low level exposure at doses that do not inhibit AChE have been reported to cause toxicity (Slotkin et al., 2006), prompting search for other mechanisms of CPF toxicity. The induction of oxidative stress is one of the mechanisms implicated in OP-induced toxicity (Gultekin et al., 2001; Ambali et al., 2007; 2010a; 2010b; 2010c; 2011; Verma et al., 2007). Oxidative stress, which results from imbalance in the body's oxidants and antioxidants in favor of the former, is known to induce cellular damage (Halliwell and Gutteridge, 2007). Under normal circumstances, the body is endowed with effective antioxidant systems to combat the menace of oxidative stress. However, in extreme oxidative challenge, such as those observed in pesticide poisoning (Saxena and Garg, 2010), the body's antioxidants machineries are overwhelmed. Under this circumstance, therefore, there is the need to supply the body with exogenous antioxidants.

Epidemiological and experimental studies have shown that CPF exposure impairs male reproductive activities causing low sperm count and altering the concentration of male sex hormones (Meeker et al., 2004; 2006; Joshi et al., 2007; Fattahi et al., 2009; ElKashoury and El-Din, 2010). The role played by some organs, especially the pituitary gland and testes in enhancing reproductive performance cannot be overemphasized. Although few studies have elaborated the role of oxidative stress in adverse reproductive outcomes, the mitigating effect of antioxidants has not been fully explored.

Vitamin E is a lipid soluble vitamin that has been reported to play a major role in preventing oxidative damage to membrane lipids by scavenging free radicals (Brigelius-Flohe and Traber, 1999). It is regarded as the most potent, lipid-soluble, chain-breaking antioxidant in nature, protecting cell membrane components from damage by oxidant agents (Brigelius-Flohe and Traber,
1999). Earlier studies have shown the ability of vitamin E to protect tissues from lipoperoxidative changes induced by OP insecticides on the red blood cells (Yavuz et al., 2004) and the brain (Ambali, 2009). Therefore, the present study evaluated the mitigating effects of vitamin $\mathrm{E}$ on oxidative changes in the pituitary gland and testes induced by chronic CPF exposure in Wistar rats. This study will serve as a prelude to evaluating the effect of vitamin $\mathrm{E}$ in mitigating adverse reproductive consequence instigated by chronic CPF exposure.

\section{MATERIALS AND METHODS}

Experimental animals: Twenty adult male Wistar rats (8-10 weaks), weighing 116-151g, obtained from animal house of the Department of Veterinary Physiology and Pharmacology, Ahmadu Bello University, Zaria, Nigeria were used for the experiment. They were housed in plastic cages in the Department and were fed on standard rat pellets while water was provided ad labium.

Chemicals: Commercial grade CPF, TERMICOT ${ }^{\circledR}$ (Sabero Organics, Gujarat, India), was obtained as a $20 \%$ emulsifiable concentrate and was reconstituted in soya oil to make $10 \%$ stock solution. Vitamin E Envirose- $100^{\circledR}$ (100 mg capsule ${ }^{-1}$ ) (XL Laboratories PVT. Ltd., Rajasthan, India) was reconstituted in soya oil to $100 \% \mathrm{v} / \mathrm{v}$ prior to daily administration. All other Achemicals used in the study were of analytical grade.

Animal treatment schedule: The rats were divided at random into 4 groups of 5 animals in each group and were given the following regimens: Group I (S/oil) was administered soya oil $\left(2 \mathrm{~mL} \mathrm{~kg}^{-1}\right)$; Group II (VE) was given vitamin $\mathrm{E}\left(75 \mathrm{mg} \mathrm{kg}^{-1}\right)$; Group III (CPF) was administered CPF $\left(10.6 \mathrm{mg} \mathrm{kg}^{-1} \sim 1 / 8\right.$ th $\mathrm{LD}_{50}$ (Ambali, 2009)) while Group IV (VE+CPF) was pretreated with vitamin $\mathrm{E}$ (75mg kg $\mathrm{mg}^{-1}$ ) and then exposed to CPF (10.6 $\mathrm{mg} \mathrm{kg}^{-1}$ ), 30 min later. The regimens were administered by gavages once daily for a period of 15 weeks. At the end of the treatment period, the rats were sacrificed by jugular venesection following light chloroform anesthesia. The animals were dissected and the pituitary glands and the testes isolated.

Tissue preparations: The pituitary gland and testes were weighed and each tissue was homogenized in a known volume $\left(5 \mathrm{mg} \mathrm{mL} \mathrm{m}^{-1}\right)$ of ice-cold phosphate buffer to make $5: 1 \mathrm{w} / \mathrm{v}$. This was then centrifuged at 
$2000 \mathrm{~g}$ for $10 \mathrm{~min}$. The supernatant was subsequently used for the analysis of concentration of MDA and the activities of Superoxide Dismutase (SOD) and Catalane (CAT).

Evaluation of pituitary gland and testicular lipid per oxidation: The Malonaldehyde (MDA) concentrations in the testicular and pituitary gland tissue samples as an index of lipperoxidation were evaluated using the double heating method of Draper and Hadley (1990). The principle of the method is based on spectrophotometric measurement of the colour developed during the reaction of Thiobarbituric Acid (TBA). Briefly, the supernatants from the pituitary gland and testicular tissue homogenates $(0.5 \mathrm{~mL})$ were respectively mixed with $1 \mathrm{~mL}$ of $10 \%$ Trichloroacetic Acid (TCA) and $1 \mathrm{~mL}$ of $0.67 \%$ Thiobarbituric Acid (TBA), the mixture from each of the organs was heated in boiling water for $15 \mathrm{~min}$, centrifuged at $800 \mathrm{~g}$ for 5 min and the supernatant collected. The levels of the Thiobarbituric Acid Reactive Substance (TBARS), malonaldehyde, in the supernatants were determined by measuring the absorbance using a UV spectrophotometer $\left(\mathrm{T} 80^{+} \mathrm{UV} / \mathrm{VIS}\right.$ Spectrometer, PG instruments Ltd., U.K.) at $532 \mathrm{~nm}$. The concentration of MDA was calculated by the absorbance coefficient of MDA-TBA complex $1.56 \times 10^{5} \mathrm{~cm}$ and expressed as $\mathrm{nmol} / \mathrm{mg}$ of tissue protein. The protein content of the tissues was determined using the method of Lowry et al. (1951).

Evaluation of the activities of pituitary and testicular superoxide dismutase: The superoxide dismutase activities were analyzed from supernatants of the pituitary gland and testicular homogenates using NWLSS $^{\mathrm{TM}}$ Superoxide Dismutase Activity Assay Kit (Northwest Life Science Specialties, LLC, 5131 NE 94th Avenue, Suite 201 Vancouver, WA 98662). The principle of the test was based on the monitoring of the auto oxidation rate of hematoxylin as described by Martin et al. (1987).

Evaluation of the activities of pituitary and testicular catalase: The catalase activities were analyzed from supernatants of the pituitary gland and testicular tissue homogenates using NWLSS ${ }^{\mathrm{TM}}$ Catalase Activity Assay Kit (Northwest Life Science Specialties', LLC, 5131 Vancouver, WA 98662). The principle of the test was based on the monitoring of the consumption of $\mathrm{H}_{2} \mathrm{O}_{2}$ substrate at $240 \mathrm{~nm}$ using the method described by Beers and Sizer (1952).

Statistical analysis: The data obtained were expressed as mean \pm SEM and then subjected to one-way
Analysis Of Variance (ANOVA) followed by Turkey's post-hoc test using Graph Pad prism version 4.0. Values of $p<0.05$ were considered significant.

\section{RESULTS}

Effect of treatments on pituitary gland and testicular malonaldehyde concentrations: There was a significant $(p<0.01)$ increase in MDA concentration in the pituitary gland in the CPF group when compared to S/oil, VE or VE+CPF group (Fig. 1). There was no significant change $(p>0.05)$ in the pituitary MDA concentration in the VE+CPF group compared to the S/oil or VE group.

The testicular MDA concentration in the CPF group was significantly higher $(\mathrm{p}<0.01)$ compared to the S/oil, VE or VE+CPF group (Fig. 2). In addition, there was a significant decrease $(\mathrm{p}<0.05)$ in the testicular MDA concentration in $\mathrm{VE}+\mathrm{CPF}$ group compared to the S/oil group but no significant change ( $>0.05$ ) when compared to VE group.

Effect of treatments on pituitary gland and testicular superoxide dismutase activities: The pituitary SOD activity in the CPF group decrease significantly $(\mathrm{p}<0.05)$ when compared to S/oil or VE group. Although not significant, the activity of pituitary gland SOD activity in the VE+CPF group increased by $43 \%$ compared to CPF group. Similarly, there was no significant change $(p<0.05)$ in the SOD activity in the $\mathrm{VE}+\mathrm{CPF}$ group compared to S/oil or VE group (Fig. 3).

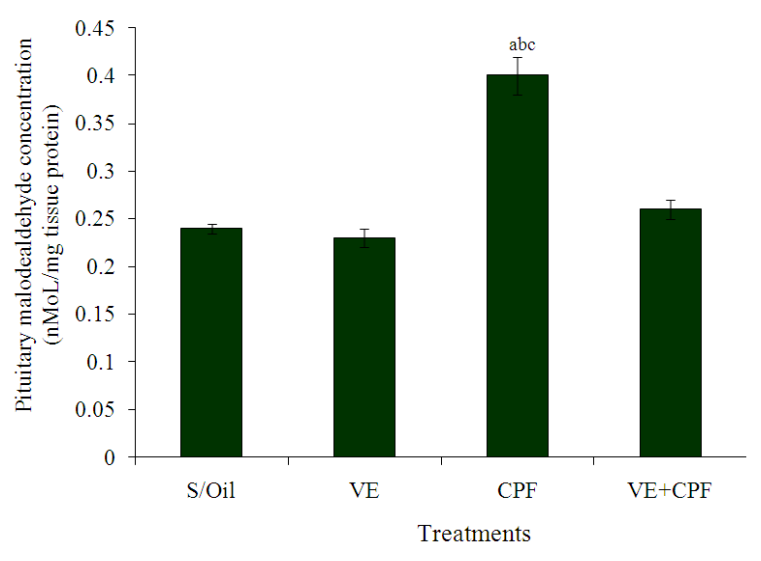

Fig. 1: Effect of chronic exposure to soya oil (S/oil), Vitamin E (VE) and/or Chlorpyrifos (CPF) on pituitary gland malonaldehyde concentration in adult male Wistar rats. ${ }^{\mathrm{ab}} \mathrm{p}<0.01$ versus S/oil, $\mathrm{VE}$ and $\mathrm{VE}+\mathrm{CPF}$ group respectively 


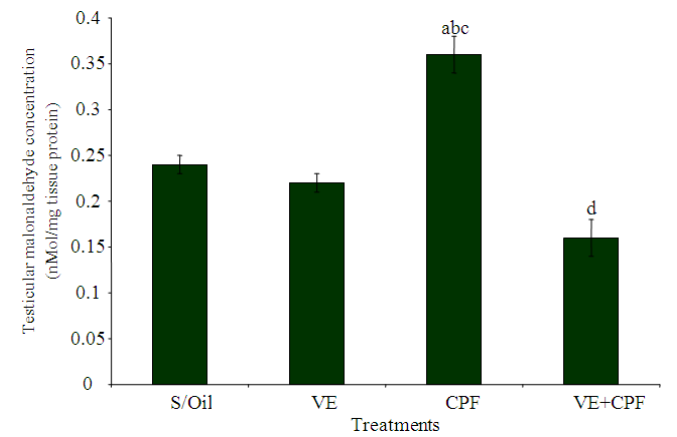

Fig. 2: Effect of chronic exposure to soya oil (S/oil), Vitamin E (VE) and/ or Chlorpyrifos (CPF) on testicular malonaldehyde concentration in adult male Wistar rats. ${ }^{\text {abc }} \mathrm{p}<0.01$ versus S/oil, VE and $\mathrm{VE}+\mathrm{CPF}$ group, respectively. ${ }^{\mathrm{d}} \mathrm{p}<0.05$ versus S/oil group

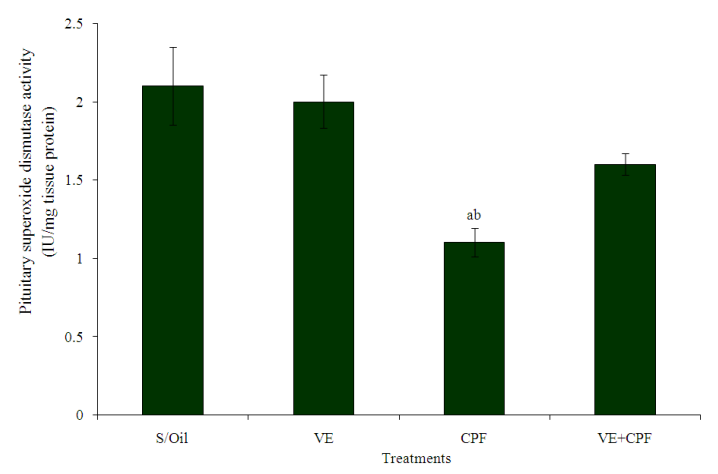

Fig. 3: Effect of chronic exposure to soya oil (S/oil), Vitamin E (VE) and/ or Chlorpyrifos (CPF) on pituitary gland superoxide dismutase activity in adult male Wistar rats. ${ }^{a b} \mathrm{p}<0.05$ versus S/oil and VE group, respectively

There was a significant $(\mathrm{p}<0.01)$ decrease in the testicular SOD activity in the CPF group relative to the S/oil, VE or VE+CPF group (Fig. 4).

Effect of treatments on pituitary gland and testicular catalane activities: The pituitary CAT activity was significantly lower $(\mathrm{p}<0.01)$ in the CPF group relative to the S/oil, VE or VE+CPF group (Fig. $5)$. There was no significant change $(p>0.05)$ in the pituitary gland CAT activities in $\mathrm{VE}+\mathrm{CPF}$ group compared to S/oil or VE group.

There was a significant decrease $(\mathrm{p}<0.05)$ in the testicular CAT activity in the CPF group relative to either the S/oil, VE or VE+CPF group (Fig. 6). There was no significant change $(p>0.05)$ in the testicular CAT activities in VE+CPF group compared to S/oil or VE group.

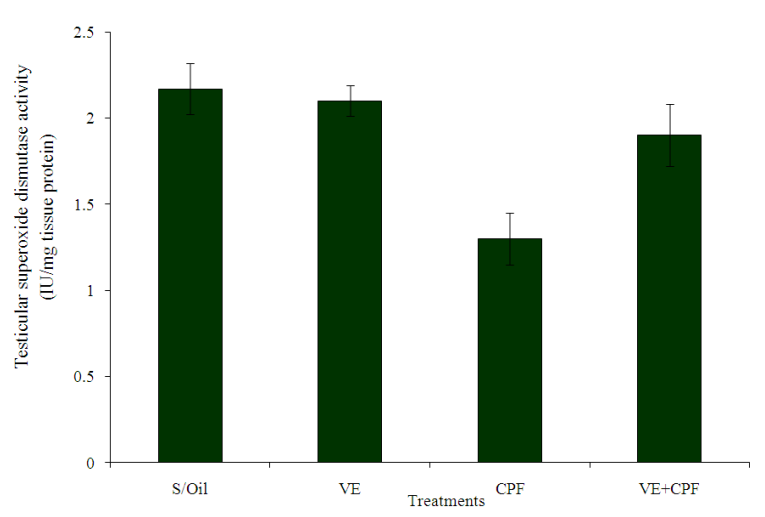

Fig. 4: Effect of chronic exposure to soya oil (S/oil), Vitamin E (VE) and/ or Chlorpyrifos (CPF) on testicular superoxide dismutase activity in adult male Wistar rats. ${ }^{a b} p<0.01$ versus S/oil and VE group, respectively. ${ }^{c} \mathrm{p}<0.05$ versus $\mathrm{VE}+\mathrm{CPF}$ group

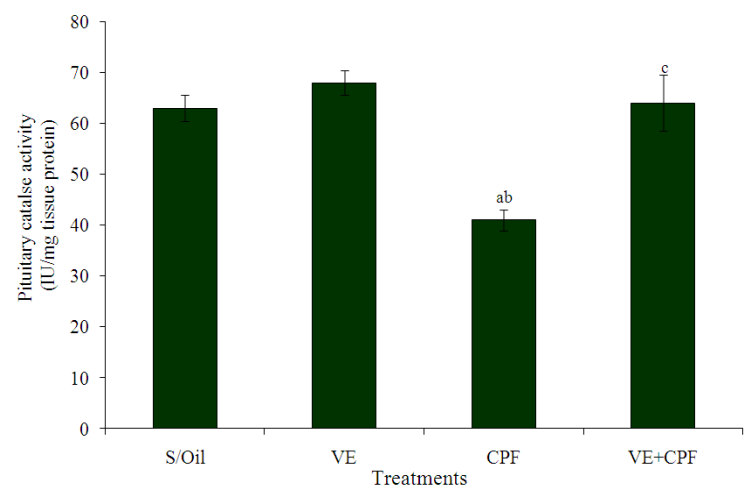

Fig. 5: Effect of chronic exposure to soya oil (S/oil), Vitamin E (VE) and/ or Chlorpyrifos (CPF) on pituitary gland catalase activity in adult male Wistar rats. ${ }^{a b c} p<0.01$ versus S/oil, VE and $\mathrm{VE}+\mathrm{CPF}$ respectively

\section{DISCUSSION}

The present study has shown a significant increase in pituitary gland and testicular MDA concentration in the CPF group, signifying the ability of the pesticide to cause oxidative changes in these organs. The increase in pituitary and testicular MDA concentrations in the CPF group recorded in the present study was in agreement with those obtained by previous workers in other tissues (Ambali et al., 2010a; 2010b; 2010c; 2011; El-Kashoury and El-Din, 2010; Farag et al., 2010). MDA is in many instances the most abundant aldehyde arising from lipid per oxidation (Verma and 
Am. J. Applied Sci., 9 (1): 75-82, 2012

Srivastava, 2003) and hence is used as an index of oxidative damage in tissues. The increased MDA concentration indicates an ongoing oxidative damage to the pituitary and testicular tissues. The brain is also known to be easily susceptible due to its inherent factors (Eren et al., 2007). The consequence of CPFinduced increased lipoperoxidation in the pituitary glands and testicular tissues is biological dysfunctions, as a result of interference with their cellular integrities and alterations in their cytostrutural organizations.

The significant decrease in the pituitary and testicular SOD activities in the CPF group has been reported previously in other tissues (Gultekin et al., 2001; Tuzmen et al., 2008). This indicates that OP either caused the reduction in the enzyme's synthesis or elevated its degradation or even caused its inactivation. Enzymatic antioxidant defence mechanisms are employed by the living organisms to alleviate the cellular assault resulting from interactions between cellular constituents and the ROS (Irshad and Chaudhuri, 2002). SOD is involved in the disputation of $\mathrm{O}_{2}^{\circ}$ to $\mathrm{H}_{2} \mathrm{O}_{2}$ and molecular oxygen (Yu, 1994). The low pituitary gland and testicular SOD activities may be related to the chronicity of the CPF exposure. The persistent increase in lipoperoxidation as exemplified by increased MDA concentration in the CPF group may have eventually resulted in a deficit SOD activities resulting from increased used and subsequent metabolic degradation. Furthermore, CPF-induced oxidative stress has been shown to lead to a shift in the expression of antioxidant genes (Slotkin et al., 2007; Slotkin and Seidler, 2007; 2009). The decrease in the pituitary gland and testicular SOD activities may also be related to the direct effect of CPF (Oncu et al., 2002).

The significant decrease in the pituitary gland and testicular CAT activities in the CPF group agreed with the result obtained by previous workers (Gultekin et al., 2001; Altuntas et al., 2002). CAT is involved in a variety of biochemical functions, but more primarily in the break-down of high levels of $\mathrm{H}_{2} \mathrm{O}_{2}$ (Betteridge, 2000; Abuja and Albertini, 2001) into $\mathrm{H}_{2} \mathrm{O}$ and $\mathrm{O}_{2}$, thereby aiding in the removal of the oxidant (Schneider and De Oliveira, 2004). The decrease in the CAT activity in the CPF group may be linked to a decrease in SOD activity, which reduces the rate of conversion of $\mathrm{O}_{2}{ }^{--}$to $\mathrm{H}_{2} \mathrm{O}_{2}$, the substrate for CAT. The lack of substrate for CAT activity eventually results in its reduced activity. Accumulation of $\mathrm{O}_{2}{ }^{\circ}$, through SOD activity inhibition has been shown to inhibit CAT activity (Kono and Fridovich, 1982), since $\mathrm{O}_{2}{ }^{-}$converts feroxy state of CAT to ferryl state, which is an inactive form of the CAT (Freeman and Crapo, 1982).

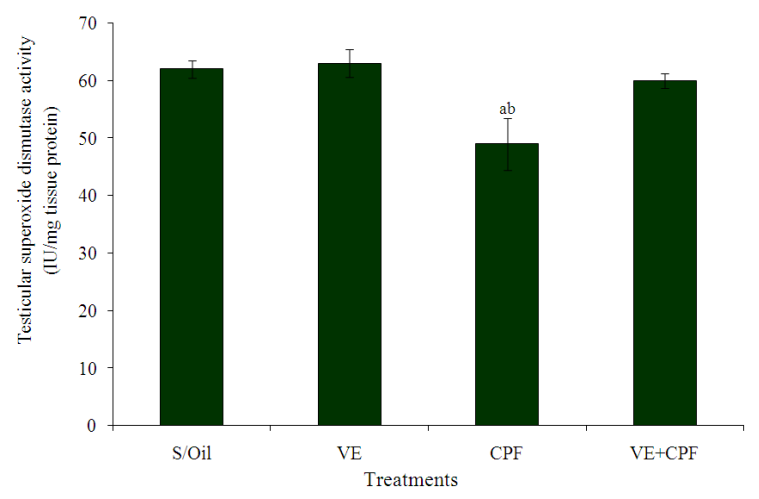

Fig. 6: Effect of chronic exposure to soya oil (S/oil), Vitamin E (VE) and/ or Chlorpyrifos (CPF) on testicular catalase activity in adult male Wistar rats. ${ }^{a c} p<0.05$ versus $\mathrm{S} /$ oil and $\mathrm{VE}+\mathrm{CPF}$, respectively. ${ }^{b} p<0.01$ versus $V E$ group

The pituitary glands play an important role in reproduction as it is responsible for release of Follicle Stimulating Hormone (FSH) and Luteinizing Hormone (LH) involved in testosterone production and spermatogenesis, respectively. Similarly, the testes in involved in testosterone and spermatogenesis Therefore, cellular integrities of the pituitary gland and the testes must be maintained for optimum reproductive performance. It is therefore conceivable that impaired reproductive performance characterized by low sperm count, low FSH, LH and testosterone concentration associated with CPF exposure (Meeker et al., 2004, 2006; Joshi et al., 2007; Fattahi et al., 2009) may have been partly due to oxidative damage to these two important organs.

Supplementation with vitamin E has however been shown to reduced the level of pituitary gland and testicular lipoperoxidation and improved SOD and CAT activities. This may be due to the antioxidant properties of the vitamin. Vitamin $\mathrm{E}$, which is a chain breaking lipophilic antioxidant, performs its free radical scavenging role within the cellular membrane. The lipophilic character of $\alpha$-tocopherol enables it to locate itself in the interior of cell membrane lipid bilayer. There, it transfers a hydrogen atom with a single electron to a free radical, thus removing the radical before it can interact with the cell membrane (Krishnamoorthy et al., 2007; Ambali, 2009). The implication of this reduced lipoperoxidative changes in both pituitary gland and the testes is that the antioxidant may mitigate some of the reproductive challenges associated with CPF exposure. The radical scavenging ability of vitamin E may have preserved the antioxidant enzymes, therefore improving their activities. 


\section{CONCLUSION}

The present study has shown that chronic CPF exposure causes oxidative changes in both the pituitary gland and the testes. Therefore, we speculate that some of the deficits in male reproductive parameters that have been previously associated with chronic CPF exposure may be partly due to this oxidative damage. Supplementation with vitamin $\mathrm{E}$ has equally been shown in the present study to mitigate the oxidative damage to the pituitary glands and testes and therefore may likely reduce adverse male reproductive performance outcome associated with CPF exposure.

Conflict of interest: The authors declare that there is no conflict of interest in this study.

\section{ACKNOWLEDGEMENTS}

The researchers are grateful to the Ahmadu Bello University Board of Research for partly funding this work. The technical support of Chief E. Nwosu and Mr. A. Olu are duly acknowledged.

\section{REFERENCES}

Abou-Donia, M.B., 2003. Organophosphorus esterinduced chronic neurotoxicity. Arc. Environ. Health, 58: 484-497. DOI: 10.3200/AEOH.58.8

Abuja, P.M. and R. Albertini, 2001. Methods for monitoring oxidative stress, lipid peroxidation and oxidation resistance of lipoproteins. Clin. Chim. Acta., 306: 1-17. DOI: 10.1016/S00098981(01)00393-X

Altuntas, I., N. Delibas and R. Sutcu, 2002. The effects of organophosphate insecticide methidathion on lipid peroxidation and anti-oxidant enzymes in rat erythrocytes: Role of vitamins E and C. Hum. Exp. Toxicol., 21: 681-685. DOI: 10.1191/0960327102ht304oa

Ambali, S.F., 2009. Ameliorative effect of vitamins C and $\mathrm{E}$ on neurotoxicological, haematological and biochemical changes induced by chronic chlorpyrifos in Wistar rats. PhD Dissertation, Ahmadu Bello University, Zaria, Nigeria.

Ambali, S.F., A.T. Abubakar, M. Shittu, L.S. Yaqub and P.I. Kobo et al., 2010a. Ameliorative effect of zinc on chlorpyrifos-induced erythrocyte fragility in wistar rats. N. Y. Sci. J., 3: 117-122.

Ambali, S.F., A.T. Abubakar, M. Shittu, L.S. Yaqub and S.B. Anafi et al., 2010b. Chlorpyrifos-induced alteration of hematological parameters in Wistar rats: Ameliorative effect of zinc. Res. J. Environ. Toxicol., 4: 55-66.
Ambali, S.F., D. Akanbi, N. Igbokwe, M. Shittu and M. Kawu et al., 2007. Evaluation of subchronic chlorpyrifos poisoning on haematological and serum biochemical changes in mice and protective effect of vitamin C. J. Toxicol. Sci., 32: 111-120. DOI: $10.2131 /$ jts.32.111

Ambali, S.F., K. Shuaibu, R. Edeh, B.C. Orieji and M. Shittu et al., 2011. Hyperglycemia induced by subchronic co-administration of chlorpyrifos and lead in Wistar rats: Role of pancreatic lipoperoxidation and alleviating effect of vitamin C. Biol. Med., 3: 6-14.

Ambali, S.F., S.A. Adeniyi, A.O. Makinde, M. Shittu and L.S. Yaqub, 2010c. Methanol extract of Phyllanthus niruri attenuates chlorpyrifos-evoked erythrocyte fragility and lipoperoxidative changes in wistar rats. Arch. Appl. Sci. Res., 2: 191-198.

Beers, R.F.J. and I.W. Sizer, 1952. A spectrophotometric method for measuring the breakdown of hydrogen peroxide by catalase. J. Biol. Chem., 195: 133-140. PMID: 14938361

Betteridge, D.J., 2000. What is oxidative stress? Metabolism, 49: 3-8. DOI: 10.1016/S00260495(00)80077-3

Brigelius-Flohe, R. and M.G. Traber, 1999. Vitamin E: function and metabolism. FASEB, J., 13: 11451155. PMID: 10385606

Casida, J.E. and G.B. Quistad, 2004. Organophosphate toxicology: Safety aspects of nonacetylcholinesterase secondary targets. Chem. Res. Toxico., 17: 983-998. DOI: 10.1021/tx0499259

Draper, H.H. and M. Hadley, 1990. Malondialdehyde determination as index of lipid peroxidation. Methods Enzymol., 186: 421-431. DOI: 10.1016/0076-6879(90)86135-I

Eaton, D.L., R.B. Daroff, H. Autrup, J. Bridges and P. Buffler et al., 2008. Review of the toxicology of chlorpyrifos with an emphasis on human exposure and neurodevelopment. Crit. Rev. Toxicol., S2: 1125. DOI: 10.1080/10408440802272158

El-Kashoury, A.A. and H.A.T. El-Din, 2010. Chlorpyrifos (from different sources): Effect on testicular biochemistry of male albino rats. J. Am. Sci., 6: 252-261.

Eren, I., M. Naziroglu, A. Demirdas, O. Celik and A.C. Uguz et al., 2007. Venlafaxine modulates -induced oxidative stress in brain and medulla of rat. Neurochem. Res., 32: 497-505. DOI: 10.1007/s11064-006-9258-9

Farag, A.T., A.H. Radwan, R. Sorour, A. El-Okazy and E. El-Agamy et al., 2010. Chlorpyrifos induced reproductive toxicity in male mice. Reprod. Toxicol., 29: 80-85. DOI: 10.1016/j.reprotox.2009.10.003 
Fattahi, E., K. Parivar, S.G.A. Jorsaraei and A.A. Moghadamnia, 2009. The effects of diazinon on testosterone, FSH and LH levels and testicular tissue in mice. Iran J. Reprod. Med., 7: 59-64.

Freeman, B.A. and J.D. Crapo, 1982. Biology of disease: free radicals and tissue injury. Lab. Invest., 47: 412-426. PMID: 6290784

Gultekin, F., N. Delibas, S. Yasar and I. Kilinc, 2001. In vivo changes in antioxidant systems and protective role of melatonin and a combination of vitamin $\mathrm{C}$ and vitamin $\mathrm{E}$ on oxidative damage in erythrocytes induced by chlorpyrifos-ethyl in rats. Arc. Toxicol., 75: 88-96. DOI: 10.1007/s002040100219

Halliwell, B. and J.M.C. Gutteridge, 2007. Free Radicals in Biology and Medicine. 4th Edn., Oxford University Press, Oxford, New York, ISBN: 9780198568681, pp: 851.

Irshad, M. and P.S. Chaudhuri, 2002. Oxidantantioxidant system: Role and significance in human body. Indian J. Exp. Biol., 40: 1233-1239. PMID: 13677624

Joshi, S.C., N. Gulati and A. Gajraj, 2005. Evaluation of toxic impacts of mancozeb on testis in rats. Asian J. Exp. Sci., 19: 73-83.

Joshi, S.C., R. Mathur and N. Gulati, 2007. Testicular toxicity and chlorpyrifos (an organophosphate pesticide) in albino rats. Toxicol. Ind. Health., 23: 439-444. DOI: 10.1177/0748233707080908

Kenaga, E.E., W.K. Whitnoy, J.L. Hardy and A.E. Doty, 1965. Laboratory tests with dursban insecticide. J. Econ. Entomol., 58: 1043-1050.

Kono, Y. and I. Fridovich, 1982. Superoxide radical inhibits catalase. J. Biol. Chem., 257: 5751-5754. PMID: 6279612

Krishnamoorthy, G., P. Venkataraman, A. Arunkumar, R.C. Vignesh and M.M. Aruldhas et al., 2007. Ameliorative effect of vitamins ( $\alpha$-tocopherol and ascorbic acid) on PCB (Aroclor 1254) induced oxidative stress in rat epididymal sperm. Reprod Toxicol., 23: 239-245. DOI: 10.1016/j.reprotox.2006.12.004

Lassiter, T.L. and S. Brimijoin, 2008. Rats gain excess weight after developmental exposure to the organophosphorothionate pesticide, chlorpyrifos. Neurotoxicol Teratol., 30: 125-130. DOI: 10.1016/j.ntt.2007.10.004

Lemus, R. and A. Abdelghani, 2000. Chlorpyrifos: An unwelcome pesticide in our homes. Rev. Environ. Health, 15: 421-433. DOI: 10.1515/REVEH.2000.15.4.421

Lowry, O.H., N.J. Rosebrough, A.I. Farr and R.J. Randall, 1951. Protein measurement with the Folin phenol reagent. J. Biol. Chem., 193: 265-275. PMID: 14907713

Martin, J.P.J., M. Dailey and E. Sugarman, 1987. Negative and positive assays of superoxide dismutase based on hematoxylin autoxidation. Arc. Biochem. Biophy., 255: 329-336. DOI: 10.1016/0003-9861(87)90400-0

Meeker, J.D., L. Ryan, D.B. Barr and R. Hauser, 2006. Exposure to non-persistent insecticides and male reproductive hormones. Epidemiol., 17: 61-68. DOI: 10.1097/01.ede.0000190602.14691.70

Meeker, J.D., L. Ryan, D.B. Barr, R.F. Herrick and D.H. Bennett et al., 2004. The relationship of urinary metabolites of carbaryl/naphthalene and chlorpyrifos with human semen quality. Environ. Health Perspect., 112: 1665-1670. DOI: 10.1289/ehp.7234

Ngoula, F., P. Watcho, M. Dongno, A. Kenfak and P. Komtchouing et al., 2007. Effects of pirimiphosmethyl (an organophosphate insecticide) on the fertility of adult male rats. Afr. Health Sci., 7: 3-9. PMID: 17604518

Oncu, M., F. Gultekin, E. Karaoz, I. Altuntas and N. Delibas, 2002. Nephrotoxicity in rats induced by chlorpyrifos-ethyl and ameliorating effects of antioxidantsy. Hum. Exp. Toxicol., 21: 223-230. DOI: 10.1191/0960327102ht225oa

Saxena, R. and P. Garg, 2010. Vitamin E provides protection against in vitrooxidative stress due to pesticide (Chlorpyrifos and Endosulfan) in goat RBC. Bull. Biosci., 1: 1-6.

Schneider, C.D. and A.R. De Oliveira, 2004. Oxygen free radicals and exercise: Mechanisms of synthesis and adaptation to the physical training. Rev. Brasília Med. Esporte, 10: 314-318.

Slotkin, T.A. and F.J. Seidler, 2007. Comparative developmental neuro-toxicity of organophosphates in vivo: Transcriptional responses of pathways for brain cell development, cell signaling, cytotoxicity and neurotransmitter systems. Brain Res. Bul.1, 72: 232-274. DOI: 10.1016/j.brainresbull.2007.01.005

Slotkin, T.A. and F.J. Seidler, 2009. Oxidative and excitatory mechanisms of developmental neurotoxicity: Transcriptional profiles for chlorpyrifos, diazinon, dieldrin and divalent nickel in PC12 Cells. Environ. Health Perspect., 117: 587-596. PMID: 19440498

Slotkin, T.A., E.A. MacKillop, I.T. Ryde and F.J. Seidler, 2007. Ameliorating the developmental neurotoxicity of chlorpyrifos: A mechanisms-based approach in PC12 cells. Environ. Health Perspect., 115: 1306-1313. DOI: 10.1289/ehp.10194 
Slotkin, T.A., E.D. Levin and F.J. Seidler, 2006. Comparative developmental neurotoxicity of organophosphate insecticides: Effects on brain development are separable from systemic toxicity. Environ. Health Perspect., 114: 746-751. DOI: 10.1289/ehp. 8828

Tuzmen, N., N. Candan, E. Kaya and N. Demiryas, 2008. Biochemical effects of chlorpyrifos and deltamethrin on altered antioxidative defense mechanisms and lipid peroxidation in rat liver. Cell. Biochem. Func., 26: 119-124. DOI: $10.1002 / \mathrm{cbf} .1411$

USEPA, 2000. Chlorpyrifos revised risk assessment and agreement with registrants. United States Environmental Protection Agency, Washington, DC.

Verma, R.S. and N. Srivastava, 2003. Effects of chlorpyrifos on thiobarbituric acid reactive substances, scavenging enzymes and glutathione in rats tissues. Indian J. Biochem. Biophys., 40: 423428.

Verma, R.S., A. Mehta and N. Srivastava, 2007. In vivo chlorpyrifos induced oxidative stress: Attenuation by antioxidant vitamins. Pesticide Biochem. Physiol., $\quad 88$ : 191-196. DOI: 10.1016/j.pestbp.2006.11.002
Vidyasagar, J., N. Karunakar, M.S. Reddy, K. Rajnarayana and T. Surender et al., 2004. Oxidative stress and antioxidant status in acute organophosphorous insecticide poisoning. Indian J. Pharmacol., 36: 76-79.

Whyatt, R.M., R. Garfinkel, L.A. Hoepner, D. Holmes and M. Borjas et al., 2007. Within-and betweenhome variability in indoor-air insecticide levels during pregnancy among an inner-city cohort from New York City. Environ. Health Perspect., 115: 383-389. DOI: 10.1289/ehp.9546

Yavuz, T., N. Delibao, B. YAldArAm, I. Altuntao and O. CandAr et al., 2004. Vascular wall damage in rats induced by methidathion and ameliorating effect of vitamins $\mathrm{E}$ and $\mathrm{C}$. Arch. Toxicol., 78: 655-659. DOI: 10.1007/s00204-004-0593-9

Yu, B.P., 1994. Cellular defenses against damage from reactive oxygen species. Physiol. Rev., 74: 139162. PMID: 8295932 